\title{
A informação como commodity: mensurando o setor de informações em uma nova economia
}

\section{Alexander Patêz Galvão}

\section{Resumo}

Este trabalho procura mostrar que a evolução tecnológica e a emergência de novas e sólidas atividades econômicas têm implicado novos modos de se mensurar os setores da economia relacionados diretamente à informação e, conseqüentemente, novas formas de se definir, ao menos do ponto de vista econômico, o que são os produtos informacionais e o que é a informação.

\section{Palavras-chave}

Setor informacional; Setor de informações; Informação como commodity; Digitalização da informação; Produtos informacionais.

\section{INTRODUÇÃO}

Constantemente, os termos "economia da informação" e "sociedade da informação" têm sido empregados como padrão heurístico para a interpretação das transformações que atualmente ocorrem na economia, na sociedade e na política em âmbito internacional.

No âmbito das atividades econômicas, é cada vez mais reconhecido o papel da informação e das trocas informacionais - a comunicação - como insumos essenciais dos modos de se produzir em sociedade. Também se reconhece a importância que os setores envolvidos direta ou indiretamente com a produção, o processamento e a distribuição de informações têm desempenhado na economia mundial. Os produtos e serviços disponibilizados por estes setores representam parcela significativa e crescente nos níveis de produção e emprego nos países mais avançados.

Se os serviços e produtos (tangíveis e intangíveis) intensivos despontam como cada vez mais importantes para a economia dos países centrais, natural é que, nestes países, as instituições que se ocupam das contas nacionais se preocupem em quantificar adequadamente a produção, o emprego e os impactos de um setor informacional (ou de informações) no conjunto da atividade econômica. As tentativas de se quantificar este setor têm variado de acordo com as atividades econômicas abarcadas nas compilações estatísticas. Estas, por sua vez, estão diretamente relacionadas às conceituações que se pretende conferir ao setor e à própria natureza da informação no que tange aos seus aspectos econômicos. Para os propósitos da argumentação, o texto que segue não se aterá à variedade destas conceituações, mas enfocará o recente trabalho realizado na América do Norte pelos sistemas nacionais de contas dos três países da região.

\section{A IMPORTÂNCIA ECONÔMICA DE UM SETOR DE INFORMAÇÕES}

Com efeito, dados compilados pela World Information Technology and Services Alliance (WITSA) mostram que os setores envolvidos com as Tecnologias de Informação e Comunicação (TIC) representavam cerca de $6 \%$ do PIB global em 1997 e cresciam $27 \%$ mais rápido do que a economia mundial em seu conjunto (WITSA, 1998). Ainda segundo a mesma instituição, os gastos mundiais em (TIC)* em 1997 (US\$1,8 trilhões) foram 40\% superiores aos gastos de 1992.

O Departamento de Comércio Norteamericano tem creditado o desempenho econômico recente dos Estados Unidos ao crescimento dos setores ligados às novas tecnologias de informação. Assim, as indústrias ligadas às Tecnologias de Informação (TI) foram apontadas como responsáveis diretas por um quarto do crescimento econômico ocorrido nos Estados Unidos a partir de 1995, em uma dinâmica que pode ser verificada desde a década de 80: em 1985 estas indústrias res-

\footnotetext{
* A classificação das TIC feita pela WITSA é semelhante à classificação das TI feita pelo Departamento de Comércio norte-americano, mas acrescenta também os serviços de telecomunicações e os equipamentos de escritó rio. Os dados da WITSA foram compilados pelo IDC (International Data Corporation). Para maiores detalhes, ver WITSA (1998).
} 
pondiam com 4,9\% do PIB norte-americano, em 1993 passaram a representar 6,9\% e, em 1998, estimava-se que representassem 8,2\% da economia do país, ou cerca de US $\$ 680$ bilhões (US Departament of Commerce, 1998).

Os dois exemplos anteriores apontam, indubitavelmente, para uma tendência do crescimento dos setores econômicos ligados, de alguma forma, à informação. No entanto, as classificações destas instituições diferem quanto às metodologias que foram utilizadas para a compilação dos dados, mostrando, assim, resultados diversos, não exatamente comparáveis entre si. Os números do Departamento de Comércio dos EUA compreendem hardware, software e serviços relacionados, equipamentos e serviços de comunicação. Para esta instituição, os serviços relacionados às telecomunicações e à radiodifusão são selecionados como indústrias $\mathrm{TI}$ somente quando abarcam as "infra-estruturas"*: Os dados da WITSA sobre as instituições denominas TICs abarcam, também, os serviços de telecomunicações e os equipamentos para escritório.

Classificar adequadamente um "macrossetor de informações", ou as Tecnologias de Informação, ou ainda o que significa exatamente as Tecnologias de Informação e Comunicação tem sido um desafio para as várias organizações que tratam, nos países e em âmbito internacional, das normatizações e estatísticas sobre as variadas atividades econômicas. Por possuir uma natureza imaterial, a informação, lato sensu, nem sempre está consubstanciada na forma de bens tangíveis, ou serviços de fácil mensuração. As classificações propostas pelas duas instituições acima, por exemplo, desconsideram grande quantidade de setores e atividades econômicas que estão envolvidos na produção de conteúdos informativos, como as indústrias editorial e do audiovisual. De outra forma, algumas instituições e pesquisadores tendem a incluir como atividades informacionais tudo o que diz respeito a conhecimento e saber. Outros ainda detêm-

\footnotetext{
* Para maiores detalhes, ver U.S. Departament of Commerce (1998), apêndice A1.
}

se na ubiqüidade crescente dos microprocessadores privilegiando a contabilização da produção de circuitos e aparelhos microeletrônicos leves (commodities) e pesados e as indústrias correlatas a essa produção*.

Tais preocupações não são recentes e refletem a importância que as atividades informacionais vêm adquirindo na economia desde a década de 60 . Fritz Machlup, nos anos 60 e Marc Porat, nos anos 70 foram os primeiros a tentar mensurar um setor de informações na economia. Este último constatou que o setor informacional (em contraposição à agricultura, indústria e serviços) seria responsável por $54 \%$ da renda dos norte-americanos em 1974 e cresceria a taxas mais elevadas do que os outros setores ${ }^{\star *}$.

\section{NOVOS DESAFIOS PARA A CLASSIFICAÇÃO DE UM SETOR DE INFORMAÇÕES}

Os desafios em delimitar de forma adequada o setor de informações têm crescido nos últimos anos. As atividades envolvidas com a informática e com as telecomunicações têm convergido, paulatinamente, desde o desenvolvimento do código de modulação por pulsos no final da década de 50 . A partir da década de 80, a incorporação paulatina das tecnologias digitais $^{\star \star *}$ nas atividades de produção, processamento, transporte, distribuição e comercialização de conteúdo informacional ${ }^{* * * *}$, assim como a emergência de novas arquiteturas de construção de redes (cabos óticos, satélites mais potentes), potencializou

\footnotetext{
* Este foi o enfoque adotado pela OCDE no início da década de 1990, segundo Houghton at al. (1996).

** Ver Malin (1994) e Houghton at al. (1996).

*** As vantagens da tecnologia digital sobre a tecnologia analógica para o trato com informações mostraram-se evidentes - facilidades de manipulação, processamento e cópia de qualquer tipo de dados (textos, sons, imagens e vídeo), facilidades de compressão para armazenar e para transmitir informações e transmissões com menores possibilidades de interferências. Sobre os vários aspectos nos quais se desdobra o processo de digitalização de todo tipo de informações, ver o excelente trabalho de Davis e Stack (1996).

**** Texto, áudio, audiovisual ou multimídia de caráter informativo, educacional ou de entretenimento.
}

substancialmente as possibilidades de acesso, de produção e de distribuição de informações, seja sob formatos antigos, seja sob novos formatos. Assim, um movimento convergente, pontuado pelo crescimento da multimídia interativa* (essencialmente Internet e tecnologias correlatas), tem abarcado, também, vários provedores de conteúdo informacional, que trazem consigo a possibilidade de novos produtos e serviços intensivos em informação.

A convergência proporcionada pela tecnologia digital e pela emergência da multimídia interativa têm se dado não somente em nível tecnológico. Dá-se também no âmbito dos novos mercados e dos novos serviços que podem ser ofertados pelas empresas de conteúdo informativo, telecomunicações e de tecnologias de informação. É assim, por exemplo, que operadores de redes de cabo passam a oferecer aos seus assinantes telefonia e acesso ultra-rápido à Internet, empresas tradicionais de informática compram empresas de televisão aberta (broadcast), que empresas de telefonia de longa distância começam a investir em produção audiovisual e a formar parcerias e alianças com empresas de software e de mídia.

Deste modo, estas "convergências" nos âmbito das tecnologias, das redes e dos serviços têm implicado, em nível mundial, confluência de interesses recíprocos e de capitais de empresas possuidoras de diferentes competências - em telecomunicações, em informática ou na mídia - em busca de mercados (tornados) comuns. Em meio a um ambiente caracterizado pela emergência de novos serviços, provedores de conteúdos diversos, provedores de acesso às redes e especialistas em determinadas aplicações passam a cooperar entre si na busca de sinergias comuns. Assim, a multimídia interativa e o ciberespaço mostram-se como o meio ambiente privilegiado para que ocorra efetiva convergência entre as empresas dos três setores supracitados**.

\footnotetext{
* Sobre a multimídia interativa, ver Galvão (1998, cap. 3).

** Sobre os vários aspectos da convergência, ver Galvão (1998).
} 
Em função das transformações tecnológicas e econômicas envolvendo os setores de informática, as telecomunicações e a mídia, novas classificações para o setor de informações têm sido propostas. A formalização mais efetiva neste sentido vem da América do Norte.

Nos Estados Unidos, o US Census Bureau, em conjunto com instituições similares no México e no Canadá, promoveu, em 1997, grande revisão estrutural das normatizações classificatórias para as indústrias - a primeira revisão desta natureza desde a criação da Standard Industrial Classification (SIC) na década de 30 . As novas normatizações, sob a denominação de North American Industry Classification System (NAICS), promoveram clara delimitação de um setor de informações*. Na classificação do NAICS para o setor de informações, estão os setores de telecomunicações, radiodifusão, produção de software, a indústria editorial $^{* *}$, a produção fonográfica e de conteúdo audiovisual ${ }^{* \star *}$ e os serviços de informação e processamento de dados.

Reconhecendo as qualidades intangíveis dos produtos (e serviços) de informação, o NAICS deixa de fora do setor várias atividades manufatureiras baseadas em tecnologias de informação (informática), tais como a fabricação de semicondutores e produção de equipamentos para telecomunicações e radiodifusão, normalmente incluídas em estatísticas de outras instituições $^{\star * * *}$. A classificação do NAICS também não inclui as atividades científicas e de consultoria, as atividades

\footnotetext{
* No México, o mesmo setor é chamado de Información en Medios Masivos e, no Canadá, de Information and Cultural Industries.

** Em indústria editorial estão incluídas as atividades de editoração e publicação e excluídas as atividades relacionadas à impressão de livros e materiais gráficos, classificadas como atividades manufatureiras.

*** Não estão incluídas, nesta classificação, as atividades de prensagem de CDs e a produção de equipamentos para filmagem

**** A classificação do NAICS não inclui também as empresas de consultoria, as atividades científicas, as atividades ligadas à publicidade, marketing e propaganda, as atividades relacionadas a eventos culturais como shows, performances, artes plásticas, nem ainda as atividades relacionadas à impressão de livros e materiais gráficos.
}

ligadas à publicidade, marketing e propaganda, as atividades relacionadas a eventos culturais como shows, performances, artes plásticas, nem ainda as atividades relacionadas à impressão de livros e materiais gráficos.

\section{O novo valor dos conteúdos informacionais}

O novo sistema contábil norte-americano é também resposta ao reconhecimento do maior crescimento econômico das atividades ligadas estritamente à produção dos conteúdos informacionais (produtos e serviços intangíveis) frente àquelas atividades relacionadas à construção da infraestrutura de (tele)comunicações e das plataformas técnicas necessárias à produção e circulação das informações (produtos tangíves, tais como PCs, aparelhos eletrônicos e de telecomunicações etc.).

Esta constatação pode ser verificada em estatísticas de outras regiões e países. Na União Européia, os setores envolvidos com manufatura e serviços relacionados às tecnologias de informação, telecomunicações e mídia (produção de conteúdos informacionais) faturaram, em 1995, 812 biIhões de euros* ${ }^{*}$. Deste total, a indústria do audiovisual e a indústria editorial correspondiam ao maior percentual, cerca de $25 \%$ ** (Squire Sanders \& Dempsey, Analysys, 1998).

O Ministério dos Correios e das Telecomunicações do Japão também realizou projeções que mostram o crescimento do valor da produção dos conteúdos informacionais. Em um macromercado que os japoneses classificaram como de "infocomunicações", segmentado entre conteúdos informacionais (possíveis de serem distribuídos via redes), plataformas técnicas (eletrônicos de consumo, equipamentos terminais etc.) e distribuição (a infraestrutura das redes), o valor dos conteúdos cresceria, em relação a outros

\footnotetext{
* O equivalente a US $\$ 862$ bilhões a preços de 29 de abril de 1999 ( 1 Euro = 1,061 dólares).

** O restante estava dividido entre marketing e propaganda $(19,46 \%)$, telecomunicações $(19,01 \%)$, hardware, software e serviços correlatos $(16,13 \%)$, distribuição de conteúdos e produtos de informação, eletrônicos de consumo e equipamentos de escritório.
}

segmentos, de um percentual de $33,5 \%$, em 1995, para um total de $55,1 \%$, em 2010 (Ministério dos Correios e das Telecomunicações, Japão, 1998).

Nos Estados Unidos, em 1996, as principais copyright industries, também conhecidas como creative industries, ou seja, atividades que criam produtos protegidos por direitos autorais (portanto, atividades intensivas em informação), ultrapassaram as atividades manufatureiras (aviões, automóveis, alimentos etc.) no valor das vendas ao exterior realizadas pelo país, exportando US $\$ 60,18$ bilhões, empregando $2,8 \%$ da mão-de-obra e respondendo por $3,65 \%$ do PIB. As principais copyright industries relatadas pelo estudo da International Intellectual Property Alliance (IIPA) compreendem as atividades econômicas intensivas em conteúdo informativo, tais como a produção de audiovisual, livros, softwares, a indústria fonográfica etc. (IIPA, 1998).

\section{AS ESPECIFICIDADES DOS PRODUTOS INFORMACIONAIS}

Para os propósitos de mensuração do setor informacional, o NAICS definiu a informação enquanto uma commodity, uma mercadoria que é produzida, manipulada e distribuída por uma variedade cada vez maior de empresas. A mesma instituição justifica a criação de um setor de informações devido às especificidades que conferem aos produtos informacionais características bastante distintas da produção de bens e serviços tradicionais. Algumas destas características são*:

1) Diferentemente dos bens tradicionais, um produto informacional pode não estar imbuído de qualidades tangíveis, além de poder estar inteiramente desvinculado de uma forma única,

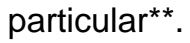

\footnotetext{
* A relação que segue é baseada em US Census Bureau (1999) e em Qhah (1999).

** Um filme pode ser visto numa sala de cinema, na televisão aberta ou por assinatura, por meio de um videocassete ou um DVD. O mesmo conteúdo de um jornal pode ser lido em um papel ou por meio eletrônico. Uma canção pode ser escutada via estação de rádio, vendida (sob a forma de um CD) em uma loja, pode estar acoplada a um conteúdo multimídia existente em um CD-ROM, ou pode ainda, para exasperação da indústria fonográfica, ser "baixada" via Internet em qualquer PC com acesso à rede.
} 
2) Ao contrário dos serviços tradicionais, a distribuição destes produtos não requer o contato direto entre 0 fornecedor (ou vendedor) e o consumidor .

3) O valor destes produtos para o consumidor não está referenciado nas qualidades tangíveis do produto, mas no seu conteúdo informacional, educacional, cultural ou de entretenimento.

4) De modo diferente dos bens e dos serviços tradicionais, os produtos culturais e informacionais podem ser replicados com grande facilidade ${ }^{*}$ e a um custo virtual extremamente baixo.

5) Um produto informacional não é "consumido" da mesma forma que um produto ou serviço tradicional. Um software ou um produto audiovisual pode ser utilizado inúmeras vezes sem que se deprecie ou perca valor.

6) As propriedades intangíveis dos produtos informacionais ou culturais imprime ao processo de produção e distribuição destes produtos características substancialmente diferentes daquelas inerentes à produção e distribuição de bens e serviços tradicionais. Somente os detentores dos direitos de propriedade sobre estes trabalhos podem transacioná-los de maneira legal. Os custos envolvidos na aquisição dos direitos geralmente são significativos, e as despesas relacionadas à distribuição destes produtos são cada vez menores**.

\footnotetext{
* As leis de proteção aos direitos de autor foram criadas em contraposição a esta facilidade. Com a eventual transformação de inúmeras formas de informação em dados binários (digitalização), as facilidades de replicação (sem perda de qualidade) estão se exacerbando. Justificam-se, desta forma, todas as pressões que os países desenvolvidos, em especial os EUA, têm desenvolvido em relação à proteção dos direitos autorais nos países periféricos.

** Devido, sobretudo, às facilidades crescentes de disponibilização dos conteúdos informacionais pela Internet.
}

7) Distribuidores dos produtos informacionais podem, facilmente, adicionar valor ao processo de distribuição*.

Uma diferenciação importante incorporada pelo NAICS é o reconhecimento do processo único e contínuo que envolve as etapas de criação, produção, manipulação e distribuição da informação sob variados formatos (texto, áudio, vídeo, multimídia, softwares), em um sentido próximo às análises baseadas em cadeias produtivas ou cadeias de valor** ${ }^{\star *}$ conceitos freqüentemente utilizados para estudos em diversos setores da atividade econômica.

\section{CONCLUSÃO}

Atualmente, a digitalização de todo tipo de sinais (texto, áudio, vídeo) e a incorporação do processamento digital nas tecnologias responsáveis pela manipulação de todos os tipos de informações proporcionam facilidades crescentes na comercialização de produtos e serviços informacionais. A tendência de novos tratamentos estatísticos para a mensuração das atividades que lidam com a criação, produção, manipulação e distribuição de produtos informacionais sob diferentes formatos estão afinadas com o crescente valor que estes produtos vêm assumindo para a economia dos países desenvolvidos.

Não é mera coincidência que os Estados Unidos, líderes na produção de produtos intensivos em informação (no sentido que é dado pelo NAICS), tenham sido os primeiros a impulsionar transformação tão significativa no seu sistema de contas nacionais. A nova classificação do setor de informações, ao reconhecer a natureza essencialmente intangível da informação, "libera" conceitualmente a mesma do seu suporte material e reflete a proeminência das redes interativas de grande capacidade de tráfego (leia-se, uma Internet mais veloz) como meio fundamental para o crescimento do setor.

\footnotetext{
* Os programadores de televisão (canais de TV), por exemplo, fazem isto veiculando anúncios publicitários aos filmes e programas exibidos, os quais não continham publicidade em sua forma original.

** Sobre cadeia de valor, ver Porter (1992).
}

Evidencia, desta forma, o empenho do governo norte-americano em alavancar o desenvolvimento da National Information Infrastructure (NII, ou Infra-estrutura Nacional de Informações), ainda no início da década de 90 e, mais recentemente, o empenho em destituir de qualquer taxação o comércio eletrônico internacional via Internet. Certamente, este será um comércio que se dará, em sua maior parte, por meio de transações de produtos intangíveis, protegidos por direitos autorais, intensivos em informação e codificados em códigos binários.

A nova classificação de um setor informacional no qual a informação é tida, essencialmente, como commodity corrobora a impressão de que a emergência de uma sociedade da informação, baseada em uma economia da informação, não parece confirmar-se na produção de semicondutores de silício, computadores e similares. O "pós-industrial" parece, desta forma, afirmar-se em uma economia da informação na qual parte significativa do valor econômico não repousará nos chips ou nas redes telemáticas, mas sim nos grandes fluxos de informações (notícias, entretenimento, educação e conhecimento em códigos digitais) proporcionados pela ligação dos microcircuitos (encapsulados em diversos produtos materiais) com as redes de telecomunicações com capacidades de tráfego e ubiqüidade crescentes. 


\section{REFERÊNCIAS BIBLIOGRÁFICAS}

1. DAVIS, J. , Stack, M. The Digital Advantage. In: Davis, J. , Hirschl, T., Stack, M. (eds) Cutting Edge: Technology, Information, Capitalism and Social Revolution. Nova lorque: Verso Books, 1996.

2. GALVÃO, Alexander P. Da Convergência Tecnológica à Convergência Empresarial: o audiovisual como espaço de acumulação na era da digitalização. Tese defendida em março de 1998 no IE/ UFRJ.

3. HOUGHTON, J. at al. Mapping Information Technology. In: Futures. 1996

4. IIPA (International Intellectual Property Alliance). New Economic Study Shows U.S. Copyright Industries Pass $\$ 278$ Billion Mark and Account for Over 3.5 Million U.S. Jobs. Disponível na Internet via WWW em <http://www.iipa.com/html/ latest_news.html > em 15 out. 1998.

5. KPMG. Public Issues Arising from Telecommunications and Audiovisual Convergence. Disponível na Internet via WWW a partir de <http://www.ispo.cec.be/ infosoc/telecompolicy/en/study-en.htm> em 03 de out. de 1996.

6. MALIN, Ana B. (1994). Economia e Política de Informação - Novas Visões da História. In: São Paulo em Perspectiva. São Paulo: Fundação SEADE, v. 8, n. 4, outdez. 1994.

7. MINGES, M., KELLY, T. The Economic Impact of the Information Society. In:

\section{Information as commodity: measuring the information sector in a new economy}

\author{
Abstract \\ This paper aims to show that the \\ technological evolution and the emerging of \\ new and solid economic activities have \\ required new ways of measuring the sectors \\ of economy related directly to information \\ and, consequently, new forms of defining, at \\ least from the economic point of view, what \\ information products are and what \\ information is.
}

\section{Keywords}

Information sector; Information as commodity; information digitization; Information products.
8. MINISTÉRIO DOS CORREIOS E DAS TELECOMUNICAÇÃO, JAPÃO. Vision 21 for Info-Communications. Disponível na Internet via WWW a partir de <http:// www.mpt.go.jp/policyreports/indexe.html> em 21 de jan. de 1998.

9. NEICE, David C. ICTs and Dematerialisation: Some implications for Status Differentiation in Advanced Market Societies. ACTS/FAIR Working Paper No.43, Brighton:SPRU, March, 1998. Disponível na Internet via WWW a partir de: <http://www.databank.it/dbc/fair/ WPSERIES.htm>

10. PORTER, Michael E. Vantagem Competitiva: Criando e Sustentando um Desempenho Superior. Rio de Janeiro: Campus, 1992.

11. QHAH, Danny T. A Ascensão dos Produtos do Saber. In: Correio da Unesco. Fev., 1999.

12. SQUIRE Sanders \& Dempsey, ANALYSYS. Study on Adapting the EU Telecommunications Regulatory Framework to the Developing Multimedia Environment. Disponível na Internet via WWW em <http://www.obs.coe.int/oea/en/actu/ index.htm> em 25 mar. de 1998.

13. U.S. Census Bureau. Proposed New Industry Structure for Information. Disponível na Internet via WWW a partir de <http://www.census.gov/epcd/www/ naics.html> em 26 abr. 1999.

14. U.S. Department of Commerce. The Emerging Digital Economy. Disponível na Internet via WWW a partir de <http:/ /www.ecommerce.gov/emerging.htm> em 10 de mar. de1998.

15. WITSA (World Information Technology and Services Alliance). Digital Planet - The Global Information Economy. Disponível na Internet via WWW a partir de <http:/ /www.witsa.org> em 17 de out. de 1998.

\section{Alexander Patêz Galvão}

Pesquisador associado ao Laboratório Território e Comunicação (LABTeC/UFRJ), mestre em economia pelo IE/UFRJ e doutorando em ciência da informação no IBICT.

E-mail: alexg@cfch.ufrj.br 